\title{
Residual Stresses Introduced to Composite Structures due to the Cure Regime: Effect of Environment Temperature and Moisture
}

\author{
N. Chowdhury, ${ }^{1}$ J. Wang, ${ }^{2}$ W. K. Chiu, ${ }^{1}$ and W. Yan ${ }^{1}$ \\ ${ }^{1}$ School of Mechanical \& Aerospace Engineering, Monash University, Clayton, VIC 3800, Australia \\ ${ }^{2}$ Aerospace Division, Defence Science and Technology Group, 506 Lorimer Street, Fishermans Bend, VIC 3207, Australia
}

Correspondence should be addressed to N. Chowdhury; nayeem.chowdhury@monash.edu

Received 21 September 2016; Accepted 18 October 2016

Academic Editor: Yuanxin Zhou

Copyright (c) 2016 N. Chowdhury et al. This is an open access article distributed under the Creative Commons Attribution License, which permits unrestricted use, distribution, and reproduction in any medium, provided the original work is properly cited.

\begin{abstract}
Material behaviour of structural components is very important to understand. In fibre reinforced polymer composite materials, this is more difficult in comparison to isotropic materials as they are made up of two constituents: the fibre and the matrix. For aerospace composite materials, the matrix is usually an epoxy resin that cures at a high temperature. This curing regime is known to introduce residual stresses to the composite material as it cools from the high cure temperature. However, how to consider these residual stresses in a structural analysis is still widely debated. In this paper, the authors investigated the offset of thermal residual strains introduced by the cure regime by the swelling of the composite when exposed to moisture.
\end{abstract}

\section{Introduction}

The use of composites in aerospace components has started to surge. This is due to their high strength to weight ratio and the ability to easily manufacture components. Despite this, composites are still relatively new compared to the metallic materials. The behaviour of composites has generally not yet been thoroughly observed over the lifespan of components which they form. In order to predict a lifespan for composite components, it is very important to accurately characterise their material behaviour.

Various failure criteria have been proposed to predict failure in composites [1]. A lot of them are established at the lamina level. Some recently developed criteria are applicable at the fibre and matrix level, such as multicontinuum theory and onset theory [2-5].

Composites are made up of two main constituents: the fibre and the matrix. Both constituents behave quite differently on their own. However, through a curing process, the two constituents are bonded to form a material that has good characteristics in its different material plane directions. Theories such as Classical Laminate Theory assist in establishing these material properties. Although these theories greatly assist in simplifying the overall material behaviour from a structural level, they are governed by assumptions. The largest of which is the treatment of the "composite material" as a "new homogeneous material" when it is still a "composite of material."

With today's computing power, modelling every strand of fibre within a composite structure is still computationally prohibitive. Thus, a compromise is needed in which the failure of a composite at its micromechanical level can be tied to behaviour of the composite at its structural level. This is where the micromechanics approach to modelling composites comes into place.

It is quite well known that the anisotropy associated with composite materials can be well predicted from a stiffness point of view, whilst accurate prediction for composite material strength is challenging. One of the large hurdles to understand these materials is nonhomogeneity which arises from the mismatch of thermal and moisture related material coefficients. One of these mismatches is termed as hygrothermal residual stresses which play a part in the mechanical strength assessment of these materials. By understanding this behaviour of the material, key assumptions can be properly made. 

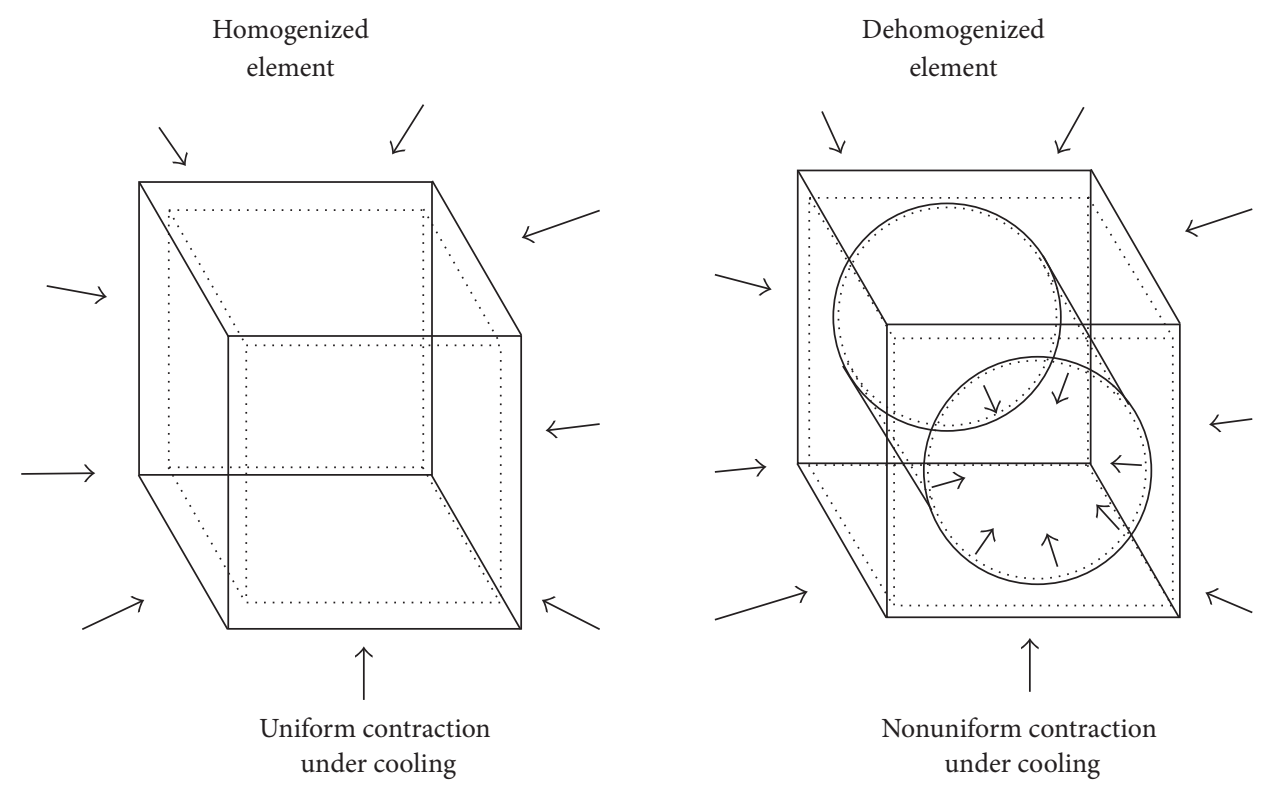

FIGURE 1: Example of contraction in a homogeneous material and nonhomogeneous material.

The thermal expansion of composites due to environmental conditions such as moisture has been examined in literature [6, 7]. The argument is that, under different humidity levels, composites will start to swell. This effect offsets the contraction a composite experiences when it cools down from a high cure temperature. In this paper, the authors present experiment results to see how the thermal residual strains introduced to composite components when they cool down from their cure temperature is offset by the swelling of the composite due to moisture absorption. The results from the experiments are further processed in a micromechanical analysis using representative volume elements in FEA. Using the results from these investigations, the method to incorporate residual stresses into a material strength analysis is presented and comparisons are made to a previously published hybrid matrix failure criterion [8-10].

\section{Hygrothermal Experiments}

The term "hygrothermal" refers to the combined effect of both thermal and moisture conditions. Hygrothermal effects are not very often included in simple analysis of composites, this is because it is an added analysis procedure that is time consuming and, in some applications, not a significant parameter. Hygrothermal stresses change in hot, cold, and room conditions. However, it should be noted that almost all material strength characterisation tests including fatigue tests are performed at room conditions. Thus, the significance and methodology to incorporate hygrothermal effects at room temperature conditions are a very important step of the material strength characterisation process.

For aircraft structures made of composite materials, there are two main stages at which hygrothermal effects take place:

(1) Hygrothermal effects during life in service.

(2) Hygrothermal effects before life in service.
The first is applicable to aircraft made from composites, where environmental conditions when flying at different altitudes expose the material to different moisture levels and temperature conditions. Moisture ingression usually continues to grow throughout life in service and often starts immediately after the curing process. As composites are often cured at high temperatures and pressures and then allowed to cool down to room temperature, there are residual contraction and expansion effects that must be examined.

At the macromechanical level, the lamina is assumed to expand or contract uniformly as shown in Figure 1. This implies that individual properties of the fibre and matrix are not directly considered. Whilst in reality, at the micromechanical level, the fibre restricts the matrix from expanding or contracting as shown in Figure 1. Thus, it is important to consider these effects and include them into micromechanical based failure criteria as given by $(1)[2,3]$ and (2) presented in strain and stress space, respectively:

$$
I_{1}^{m}=\Delta V_{\text {mechanical }}+\Delta V_{\text {thermal }}-\Delta V_{\text {hygroscopic }}
$$

where $I_{1}{ }^{m}$ is the First-Strain Invariant for the matrix. $\Delta V_{i}=$ $\varepsilon_{11 i}+\varepsilon_{22 i}+\varepsilon_{33 i}$, subscript " $i$ ": mechanical, thermal, or hygroscopic. $\varepsilon_{11}$ is the strain in the longitudinal direction. $\varepsilon_{22}$ is the strain in the transverse direction. $\varepsilon_{33}$ is the strain in the out-of-plane direction.

$$
J_{1}^{m}=\Delta S_{\text {mechanical }}+\Delta S_{\text {thermal }}-\Delta S_{\text {hygroscopic }}
$$

where $J_{1}{ }^{m}$ is the First-Stress Invariant for the matrix. $\Delta S_{i}=$ $\sigma_{11 i}+\sigma_{22 i}+\sigma_{33 i}$, subscript “ $i$ ": mechanical, thermal, or hygroscopic. $\sigma_{11}$ is the stress in the longitudinal direction. $\sigma_{22}$ is the stress in the transverse direction. $\sigma_{33}$ is the stress in the out-of-plane direction.

A general material can be considered to be able to withstand a certain amount of stress or strain referred to as 


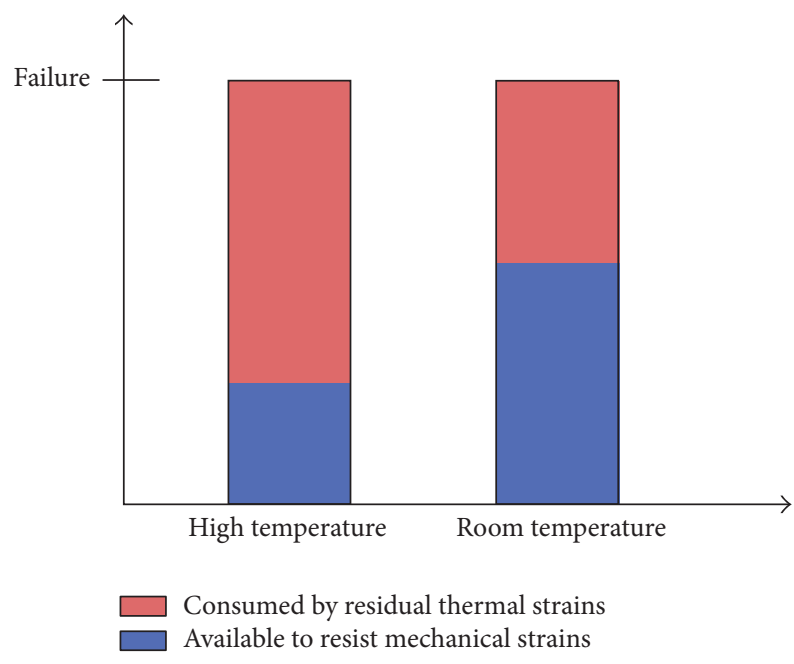

FIGURE 2: Example of proportion of material strength consumed by residual strains $[2,3]$.

its ultimate failure stress or strain [11]. The ultimate failure stress/strain can be reached by two main contributors:

(1) Mechanical stresses or strains.

(2) Residual stresses or strains.

An example of this can be seen in Figure 2.

Composites can be supplied with a range of curing temperatures. Some can be cured at room temperature and are often wet lay-ups, whilst, in most aerospace applications, composites come in the form of prepreg, where a high cure temperature is often required. Once the material has cured, the specimen starts to contract until it reaches room temperature. The rate of expansion or contraction is given by a term referred to as the "thermal expansion coefficient." Moisture effects are also introduced to a composite material before life in service. Once a composite specimen or structure is removed from its vacuum bag and oven/autoclave and allowed to rest at room temperature until it is tested or used, it starts absorbing moisture from the environment. These moisture generated residual stresses and strains are tensile in nature and thus act in the opposite direction to the thermal residual stresses-strains. This implies that some of residual stresses-strains introduced by thermal effects are relieved by moisture absorption as shown in Figure 3.

The higher proportion of thermal residual stresses-strains that is relieved by moisture absorption depends on the material. If it can be found that there is almost a one-to-one relationship between the two, then it would be appropriate to ignore any hygrothermal effects from the remainder of the material analysis. Implying that, mechanical stresses/strains would be the only contributors to failure of the lamina. This effect was investigated using EP 280 Prepreg [12].

2.1. Experiment Methodology. The aim of the investigation was to firstly observe the thermal residual strains that are introduced to a composite laminate after it has cured and cools down to room temperature. Secondly, to see how these compressive strains are offset by the composite laminate

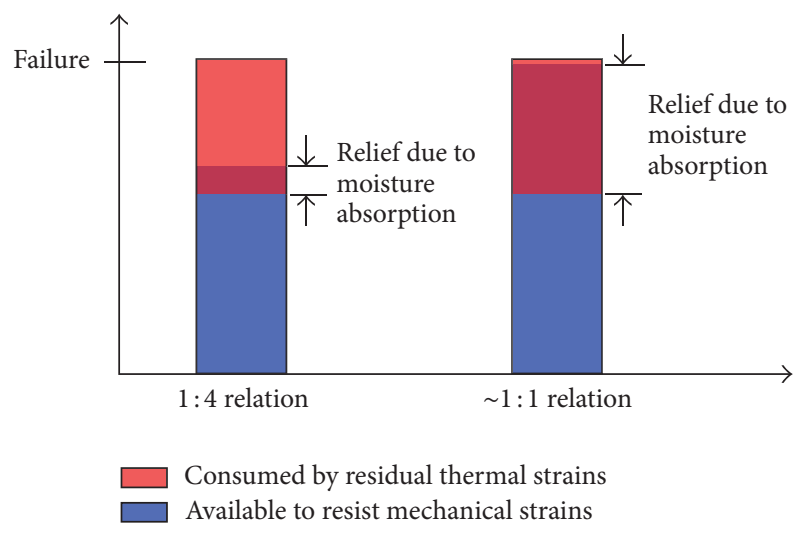

FIGURE 3: Example of proportion of thermal residual strains relieved by moisture absorption $[2,3]$.

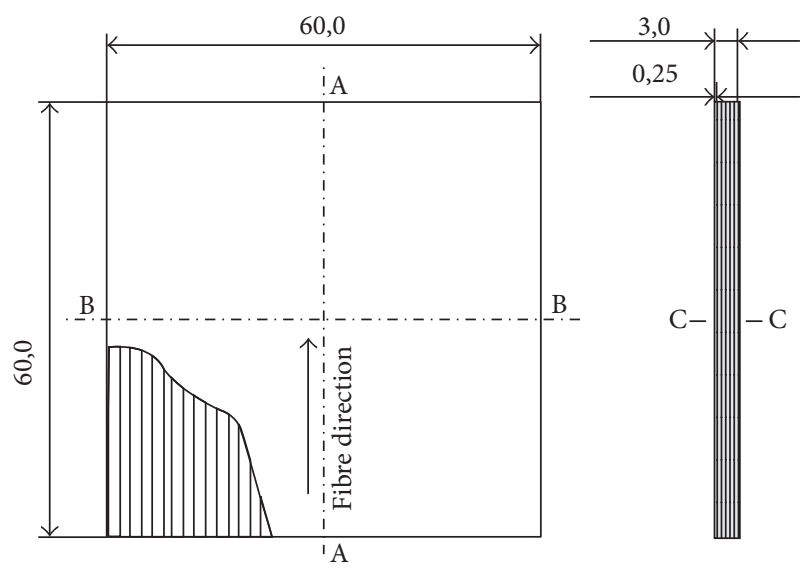

FIgURE 4: Specimen design used in hygrothermal experiments [mm].

swelling as the laminate sits at room temperature ready for being tested in the lab experiments. Two main experiments were set up:

(1) Expose a composite specimen to different temperatures.

(2) Expose a composite specimen to different moisture (humidity) levels.

Four specimens for each of the above two experiments were used in order to get an averaged result. The specimen design is shown in Figure 4 and the manufacture process is shown in Figure 5. The specimens were prepared by laying up several layers of unidirectional EP 280 Prepreg on an aluminium plate which had its contact surface lined with a Teflon sheet to assist in the release of the cured carbon plate [13]. A similar plate was placed on the top of the lay-up to provide a flat surface to both the top and bottom surfaces. Care was taken to ensure that the fibres were all aligned in the same direction. The gap between the edges of the two plates was sealed using high temperature scotch tape to prevent any resin seeping out during the cure. A small hole was punctured in the tape to allow air to escape during the vacuuming process. Once 

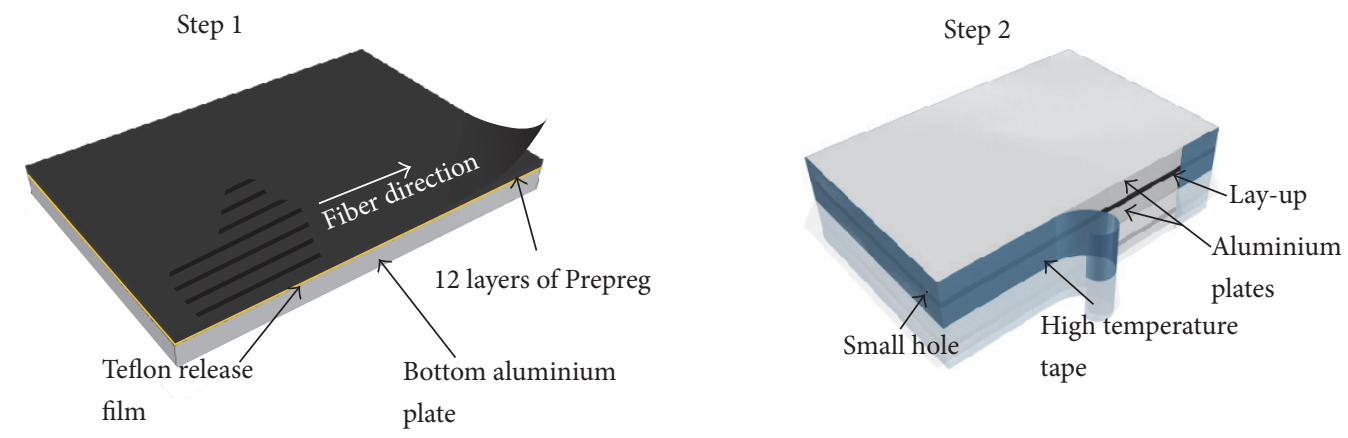

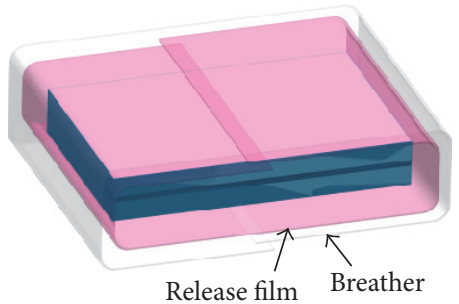

Step 3

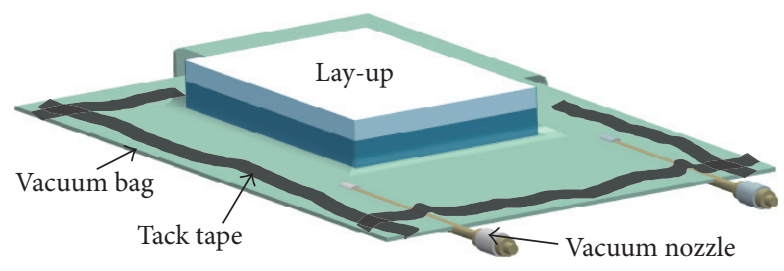

Step 4

FIGURE 5: Specimen manufacturing process.

the lay-up was complete, it was wrapped in one layer of release film followed by a layer of breather and placed in a vacuum bag. All the specimens were cured according to the manufacturer's guidelines [12]. This involved curing in an autoclave at $100 \mathrm{kPa}$ and $120^{\circ} \mathrm{C}$ for 60 minutes with a ramp-up rate of $2^{\circ} \mathrm{C} / \mathrm{min}$.

Once curing had completed, the coupon specimens were machined using a $\mathrm{CNC}$ router to the dimensions shown in Figure 4. In this figure, the positions, AA, BB, and CC, are used for all strain measurements. The three different positions correspond to the three material orientations: the longitudinal, transverse, and out-of-plane direction, respectively. Through thickness effects were not investigated as the specimen was primarily designed for measuring inplane effects. Hence, the in-plane dimensions $(60 \mathrm{~mm})$ were twenty times larger than the thickness $(3 \mathrm{~mm})$. Thus, the scatter associated with measuring through thickness effects would be quite high and hence ignored. ASTM D 5229 [14] specifies dimensions that should be considered when testing for through thickness effects. Typically, the out-ofplane behaviour for unidirectional laminate is assumed to follow the transverse behaviour and was adopted in this investigation.

Each specimen was conditioned for a certain number of days depending on how long it took to reach equilibrium. The equilibrium value was determined by the specimens' moisture content, that is, when the moisture content of the specimen changed by less than $0.02 \%$ [15]. In experiment 1 (humidity), the coupons were placed in a Thermoline temperature and humidity chamber at a fixed temperature of $80^{\circ} \mathrm{C}$. The humidity levels tested were $40 \%$ and $80 \%$. Note that, after each set of moisture experiments, the specimens were dried in an oven (similar to performing the thermal experiments). This was to ensure that the moisture contents were close to zero before starting. The drying process took up to 5 days in some cases when exposed to $80^{\circ} \mathrm{C}$. In experiment 2 , the specimen dimensions and weights were recorded at room temperature $\left(23^{\circ} \mathrm{C}\right.$ ), at $50^{\circ} \mathrm{C}$, and at $120^{\circ} \mathrm{C}$ (note: glass transition temperature, $T_{g}=143.6^{\circ} \mathrm{C}$ ). The longitudinal and transverse lengths were measured using a TESA $25-50 \mathrm{~mm}$ micrometer. The weight was measured on a Sartorius 1601 weighing scale to a precision of $0.0001 \mathrm{~g}$.

2.2. Experiment Results. On average, each moisture experiment was run for one and a half months. According to the ASTM D 5229 [14] standard, it can sometimes be misleading to assume that equilibrium has been reached by measuring a change in weight of less than $0.02 \%$. The standard suggests that a moisture content versus root of time plot should be made in order to observe an asymptotic behaviour. This is shown in Figure 6 for the various humidity levels tested.

The dimensions of the specimens at the last day at which equilibrium was reached were measured. The dimensions of the specimens were converted to strains. The results for the moisture effects are shown in Figure 7.

The same process was repeated for the thermal experiments, where the change in weight until equilibrium was recorded. The three temperatures tested were $23^{\circ} \mathrm{C}$ (room temperature), $50^{\circ} \mathrm{C}$, and $120^{\circ} \mathrm{C}$ (curing temperature). The moisture content over time is shown in Figure 8.

The specimens did not require as long of a time period to reach equilibrium when compared to the moisture experiments. On average, the specimens took less than a week. Once an asymptotic value appeared to have been reached, the experiments were stopped in order to prevent burning of the specimen from prolonged exposure to high temperatures. Note that the room temperature equilibrium level was measured after two months of a specimen sitting at laboratory 


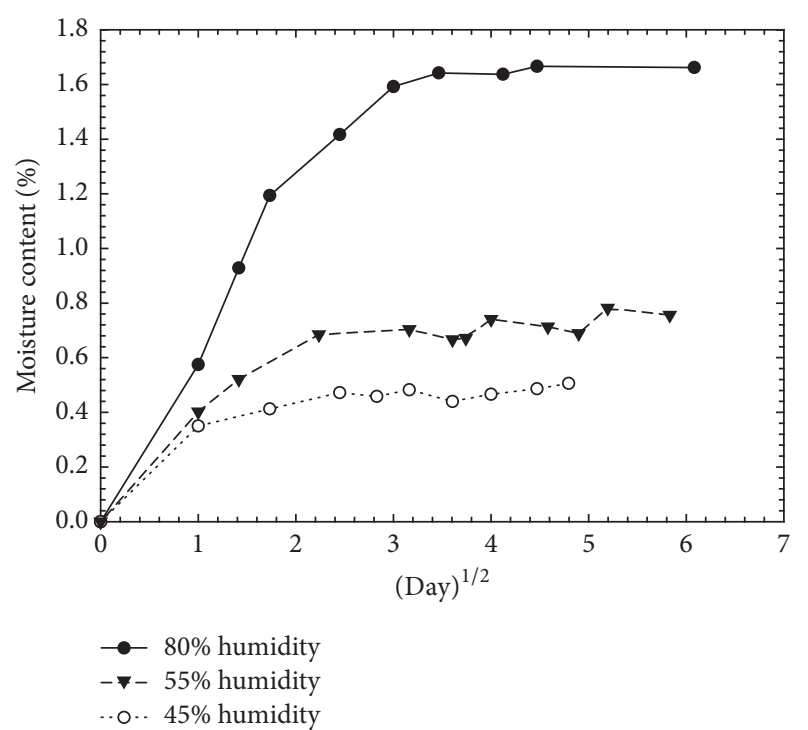

FIGURE 6: Change in moisture content over time for specimens exposed to different humidity levels.

conditions. This was to ensure that the specimen had truly reached equilibrium as laboratory conditions are important to correctly measure, as all the tensile experiments are based on laboratory conditions. The changes in the specimen's dimensions were then converted to strain and plotted against their temperatures in order to find a trend. A plot of the results are shown in Figure 9.

A final plot was made examining the percentage change in specimen weight at different humidity levels; this is shown in Figure 10.

2.3. Discussion of Experiment Results. From Figures 7(a) and 9(a), the strain results in the longitudinal direction showed a high amount of scatter and a regression analysis revealed no correlation in results. It is generally well known that the expansion along the fibre direction is quite small and difficult to measure without very precise equipment [16]. For these sets of experiments, the expansion and contraction in the fibre direction were considered to be close to zero and were ignored in the analysis.

The transverse strains introduced by the cooling and absorption of moisture by the specimens shown in Figure 9(b) showed a clear trend. A linear regression was fitted to all the results. EP280 Prepreg has a cure temperature of $120^{\circ} \mathrm{C}$ and room temperature was considered to be $23^{\circ} \mathrm{C}$, and using Figure 9(b), a compressive strain of -0.0023 was obtained. The average atmospheric humidity in the laboratory where the specimens were stored is $55 \%$ which is also based on inference. Using Figure 7(b), it was found that the specimen expands to experience a tensile strain of +0.0020 . The results are plotted in Figure 11. The contraction and expansion were found to almost entirely offset each other and thus the transverse residual strains were ignored for the composite material (EP 280 Prepreg) used in this investigation.

Using Figure 9, the thermal coefficient of expansion for EP 280 Prepreg in the transverse direction was found to be equal to $23.8 \times 10^{-6} /{ }^{\circ} \mathrm{C}$.
The offset of thermal expansion due to moisture absorption has been looked at by Tsai [17]. Their findings state that if a composite has a moisture content close to $0.5 \%$, then the thermal residual stress can be largely ignored. From Figure 10, it was found that, from the time, the specimen was cooled down and taken out of the oven and allowed to settle to room temperature, it was exposed to an initial humidity of $30 \%$ which slowly increased to $55 \%$ atmospheric humidity. The weight of the specimen increased by $0.68 \%$ due to moisture absorption. Thus, the findings were also consistent with literature [17]. In conclusion, it was found that it is appropriate to ignore hygrothermal effects for EP 280 Prepreg.

\section{Finite Element Analysis}

Based on the outcomes achieved in the experimental stage of this investigation, it was found that hygrothermal effects for EP 280 Prepreg were not significant at the laminate level when considering room temperature. However, these effects/stresses can often been amplified when looking at the individual constituents of the composite especially the matrix. Thus, a computational model needs to be able to accurately capture this effect, which is investigated in this section of the paper.

In an ideal situation, a composite would be modelled with each strand of fibre surrounded by a polymeric matrix. This would allow the stress and strain states of the fibre, matrix, and interface to be extracted separately. However, this is computationally prohibitive due to the large computing power and time required. One method that has greatly assisted in simplifying this analysis is Classical Laminate Theory (or CLT) [18]. Conventional failure models are phenomenological and rely on curve fitting parameters whose physical meanings are not always well established [19]. They determine failure at the ply level, and this prevents identification of failure in the fibre, matrix, or interface, although some efforts have been made [19]. One improvement that can be made to these theories would be the ability to separately examine the fibre and the matrix after a lamina/macromechanical analysis. This can be done using micromechanical analysis.

3.1. Representative Volume Elements. In a micromechanical analysis, the basic building block used to model a composite is referred to as a representative volume element (RVE), or, in some cases, it is referred to as a unit cell. However, the term unit cell is more suited to cases where an exact replication of a unit of the material is examined, whilst the term RVE is a representation of a unit of material. Literature has suggested that a viable solution to modelling the random distribution of fibres within a lamina can be made by modelling different shaped RVEs $[9,10]$. The three commonly employed models use a square, diamond, and hexagonal stacking configuration. These are shown in Figure 12, where dimensions of the RVEs can be calculated using

$$
\begin{aligned}
& v_{f}=\frac{\pi r_{f}^{2}}{b c}, \\
& v_{f}=\frac{2 \pi r_{f}^{2}}{b c},
\end{aligned}
$$




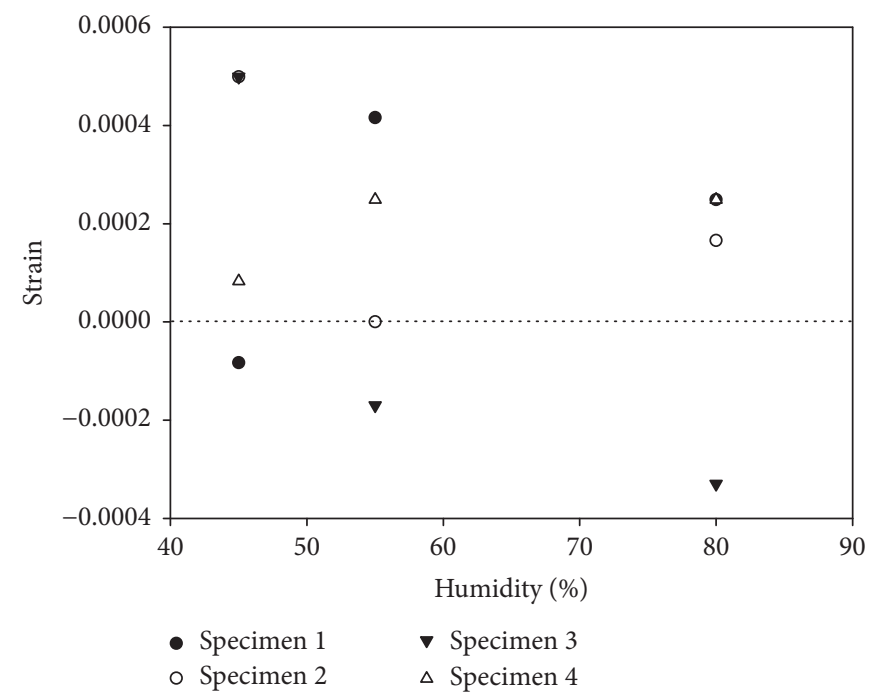

(a)

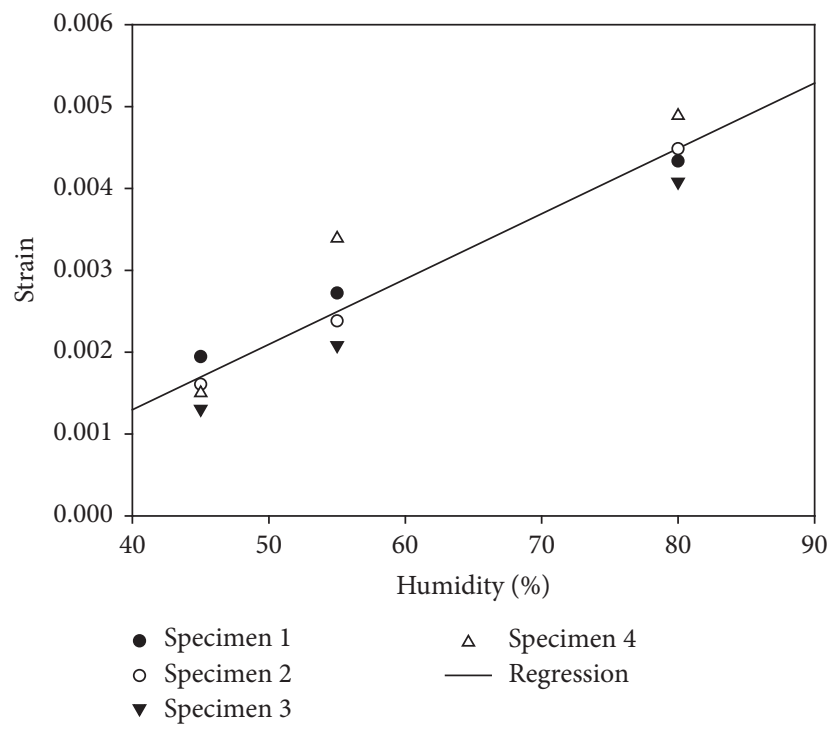

(b)

FIGURE 7: Effect of strain with respect to moisture along (a) the fibre direction and (b) transverse direction.

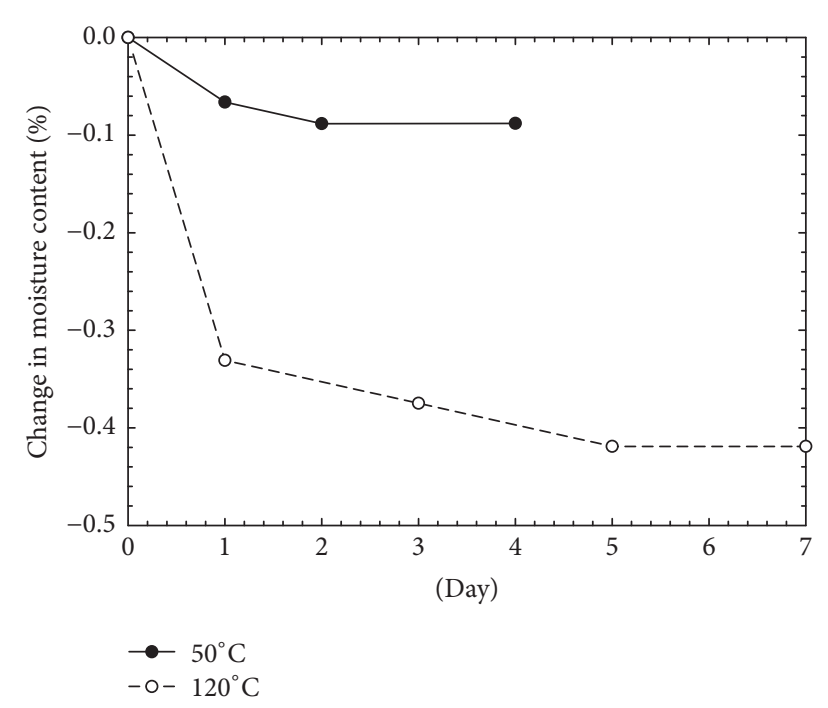

FIGURE 8: Change in moisture content over time for specimens exposed to different temperature levels.

where $v_{f}$ is fibre volume fraction, $r_{f}$ is fibre radius, $b$ is width of RVE (refer to Figure 12), and $c$ is height of RVE (refer to Figure 12).

The overall scale/dimension of the RVE is not important as all loads applied to the models were based on strains. However, care had to be taken to ensure that the RVEs were not drawn excessively small due to potential issues arising depending on the FEA package used. In this investigation, ABAQUS CAE v6.13 was used for all the analysis and the dimensions of the RVEs chosen are summarised in Table 1.

In previous investigations performed by the authors, all three RVE configurations had been modelled to examine both tensile $[9,20-22]$ and compressive failure modes of the
TABLE 1: Dimension of RVE configurations used.

\begin{tabular}{lcccc}
\hline & \multicolumn{4}{c}{ Dimensions $[\mathrm{mm}]$} \\
& " $"$ & " $b$ " & "c" & " $r_{f}$ " \\
\hline Square & 1.000 & 1.000 & 1.000 & 0.399 \\
Diamond & 1.000 & 1.000 & 1.000 & 0.282 \\
Vertical Hex & 1.000 & 1.000 & 1.732 & 0.371 \\
Horizontal Hex & 1.000 & 1.732 & 1.000 & 0.371 \\
\hline
\end{tabular}

matrix $[8,10]$. Based on those investigations it was found that the tensile quadrant of a failure envelope for the matrix in principal stress space was best modelled using the FirstStress Invariant, whilst the other 3 quadrants of the materials failure envelope could be quite accurately predicted by the Drucker-Prager failure criterion. Both of those studies have utilised the assumption of ignoring hygrothermal effects introduced by the materials cure regime as it was found that the materials moisture content was close to $0.5 \%$. However, in this paper, through utilising micromechanical analysis, the authors aim to more accurately quantify the significance of residual stresses.

A finite element analysis using a square RVE was used in this study. The square RVE was found in previous studies to give the highest stress results amongst all other fibre configurations that were used $[9,10]$; thus its analysis was sufficient to examine the significance of hygrothermal effects.

3.2. Boundary Conditions. One of the most important considerations to maintain when performing a micromechanical analysis using RVEs is to ensure periodic boundary conditions are satisfied. This means that the sides or faces of the RVE must deform in a manner that allows a deformed RVE to be stacked side by side in an array without any regions of overlap or voids. This does not necessarily mean 


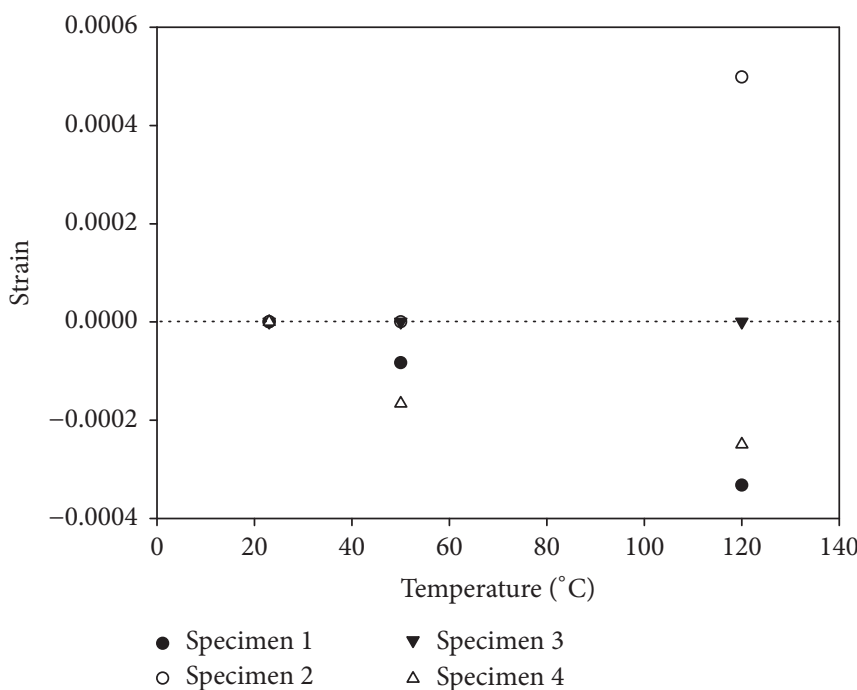

(a)

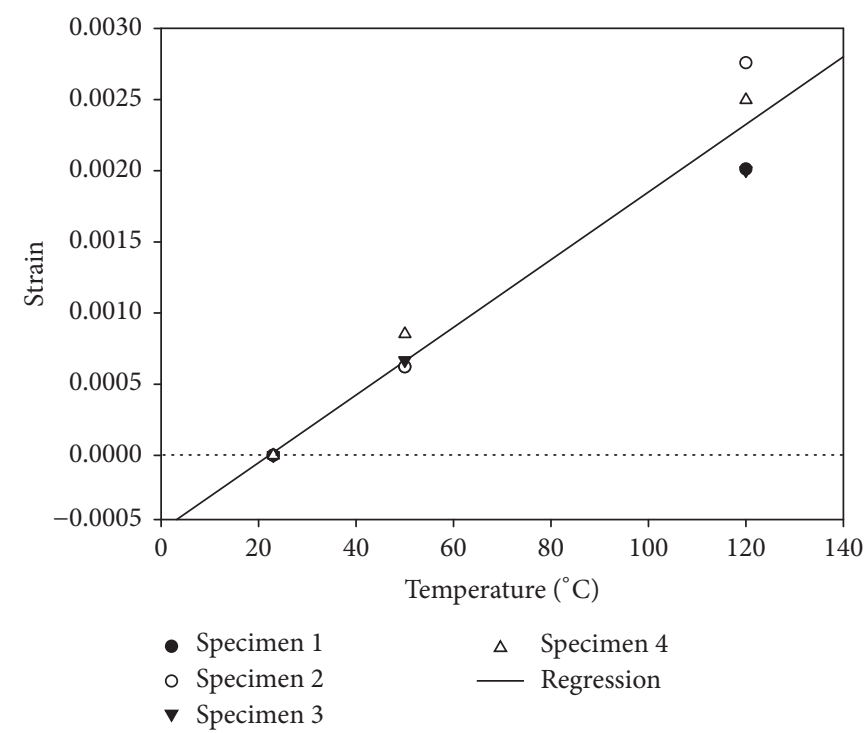

(b)

FIGURE 9: Effect of strain with respect to temperature along (a) the fibre direction and (b) transverse direction.

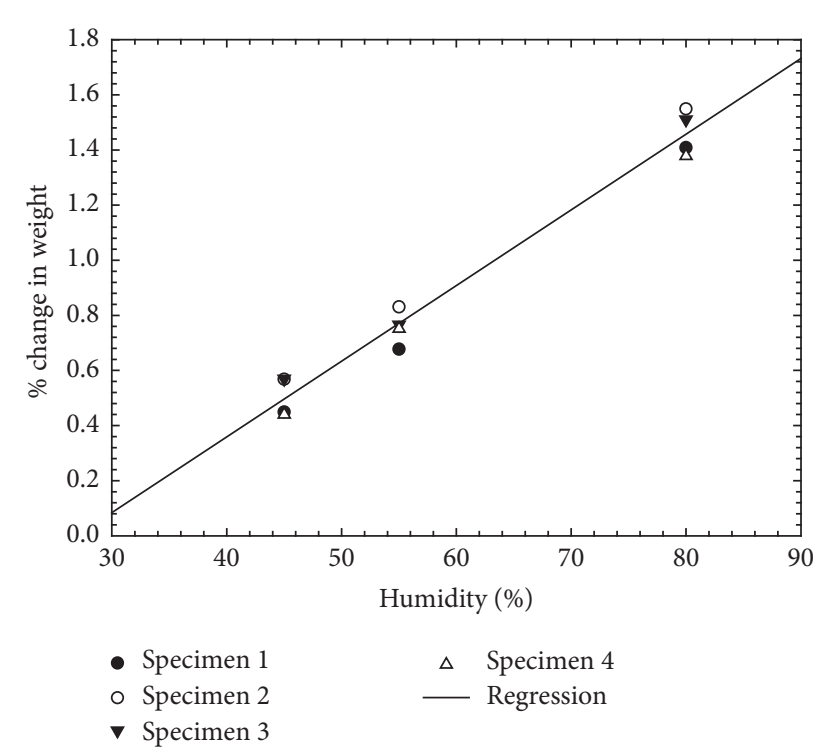

FIGURE 10: Changes in weight when specimen is exposed to varying humidity levels.

that the sides of the specimen must remain flat, although, in most cases, this is what happens. The simplest means of ensuring boundary conditions will be maintained is to apply any loads on the model as displacement loads. This ensures that deformation of corresponding faces remains flat despite the stiffness of the medium. However, in this particular investigation, modelling thermal and moisture related changes result in uneven deformation of the RVEs faces. Thus, a means of overcoming issues regarding periodic boundary conditions was to use an array of RVEs with an inner cell being of interest. An example of this type of model is shown in Figure 13. The three opposing faces of the RVE

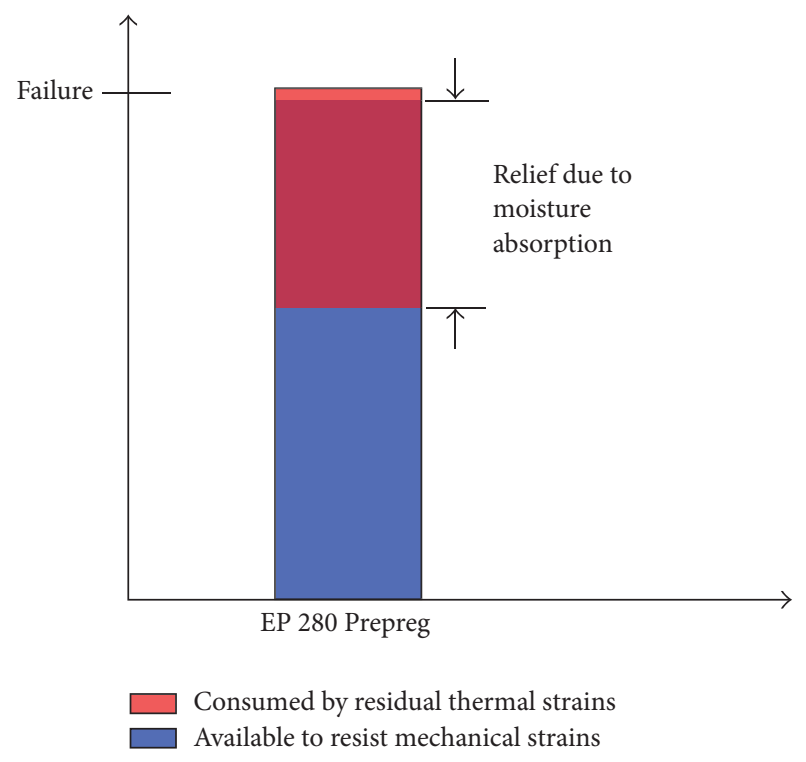

FIgURE 11: Relief in thermal residual strains in EP 280 Prepreg due to moisture absorption.

in $x, y$, and $z$ directions had symmetric boundary conditions applied, which allowed the RVE array to shrink and expand whilst restricting movement perpendicular to their planes.

This type of model does come with the cost of excessive computation time; however, as only one analysis was required in this investigation, it was considered suitable. 8-node linear brick elements with reduced integration and hourglass control (C3D8R) were used in ABAQUS v6.13. In total, 279216 elements were used in the "Full RVE," of which 10332 elements were used on the "Extracted Centre RVE."

Material properties for the fibre and the matrix used in this investigation are summarised in Table 2 [8-10]. The 


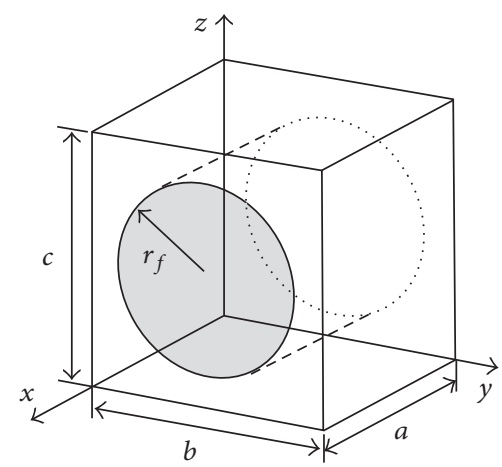

(a)

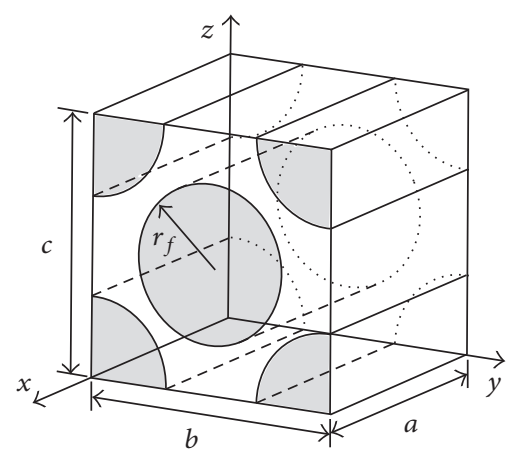

(b)

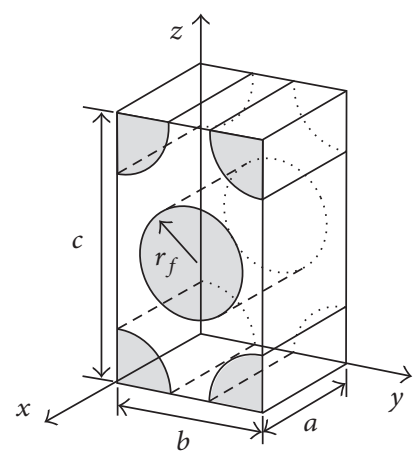

(c)

FIGURE 12: Description of dimensions for (a) a square, (b) diamond, and (c) hexagonal fibre configuration [14].

TABLE 2: Fibre and matrix properties (EP 280 Prepreg) [9].

\begin{tabular}{lcc}
\hline Property & Fibre & Matrix \\
\hline$E$ & $259 \mathrm{GPa}$ & $3.15 \mathrm{GPa}$ \\
$v$ & 0.3 & 0.3 \\
\hline
\end{tabular}

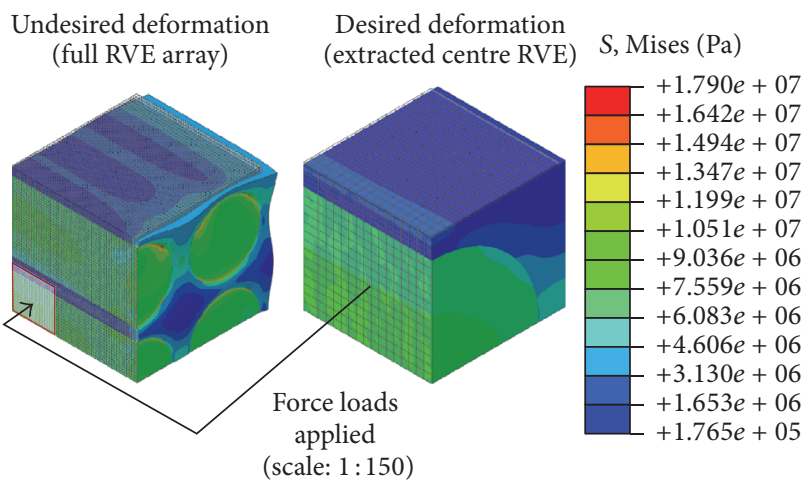

FIGURE 13: Example of maintaining periodic boundary conditions using an array of square fibre configuration RVEs with loads applied as forces.

thermal expansion and moisture expansion coefficients used for the matrix were discussed earlier in this paper to be 23.8 $\times 10^{-6} /{ }^{\circ} \mathrm{C}$ and $8 \times 10^{-5}$, respectively. The fibre was assumed to have expansion coefficients of 0 , which is consistent with values reported in literature [23].

3.3. FEA Results. The analysis was performed in ABAQUS v6.13 using the inbuilt thermal expansion module. A "Restart" command in the analysis was used to start the analysis for the moisture expansion phase of the analysis. Both phases of the experiments (i.e., the thermal contraction of the matrix as it cools down from the cure temperature to the expansion of the material as it sits at lab conditions) were modelled. Both phases of the analysis results are shown in Figures 14 and 15.

The final micromechanical RVE stress contours were plotted using the First-Stress Invariant and the DruckerPrager criteria. This is shown in Figure 16, where the results from the analysis were exported to MATLAB R2012b and
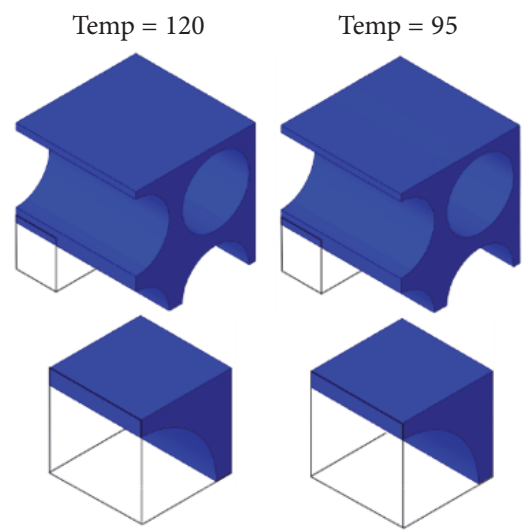

Def. scale: $1: 80$
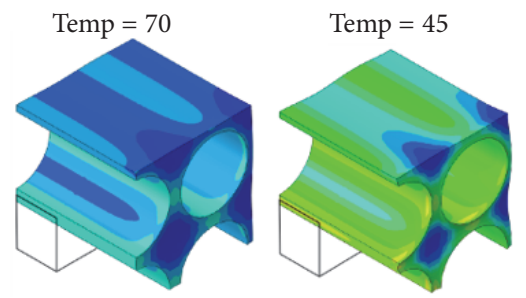

$S$, Mises (Avg: 75\%)
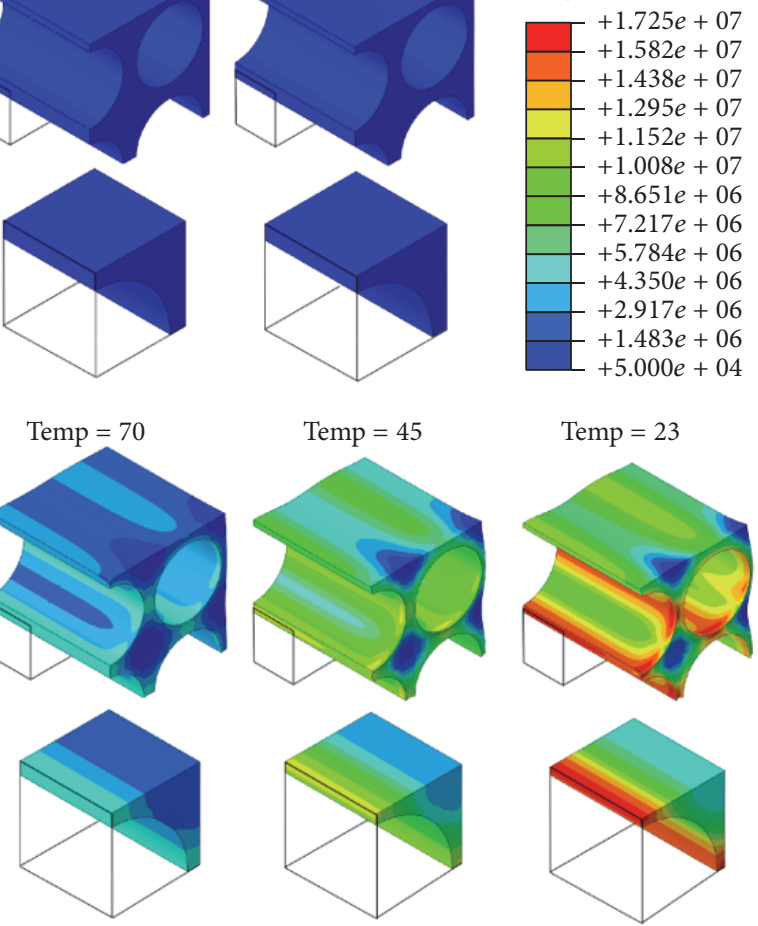

FIGURE 14: RVE under thermal contraction.

postprocessed. This final plot represents the residual stresses experienced on the matrix after cooling down from a curing temperature and then allowing it to settle at laboratory conditions where the room temperature is $23^{\circ} \mathrm{C}$ and the humidity is $55 \%$.

For ease of interpreting and viewing results, the principal stresses, First-Stress Invariant and Drucker-Prager terms at several critical locations of the RVE is shown in Figure 17 and is presented in Table 3. P1-P3 represent critical locations on the fibre-matrix interface, $\mathrm{P} 4$ and $\mathrm{P} 6$ highlight the interfibre critical locations, whilst $\mathrm{P} 5$ represents the interstitial position of the matrix. 


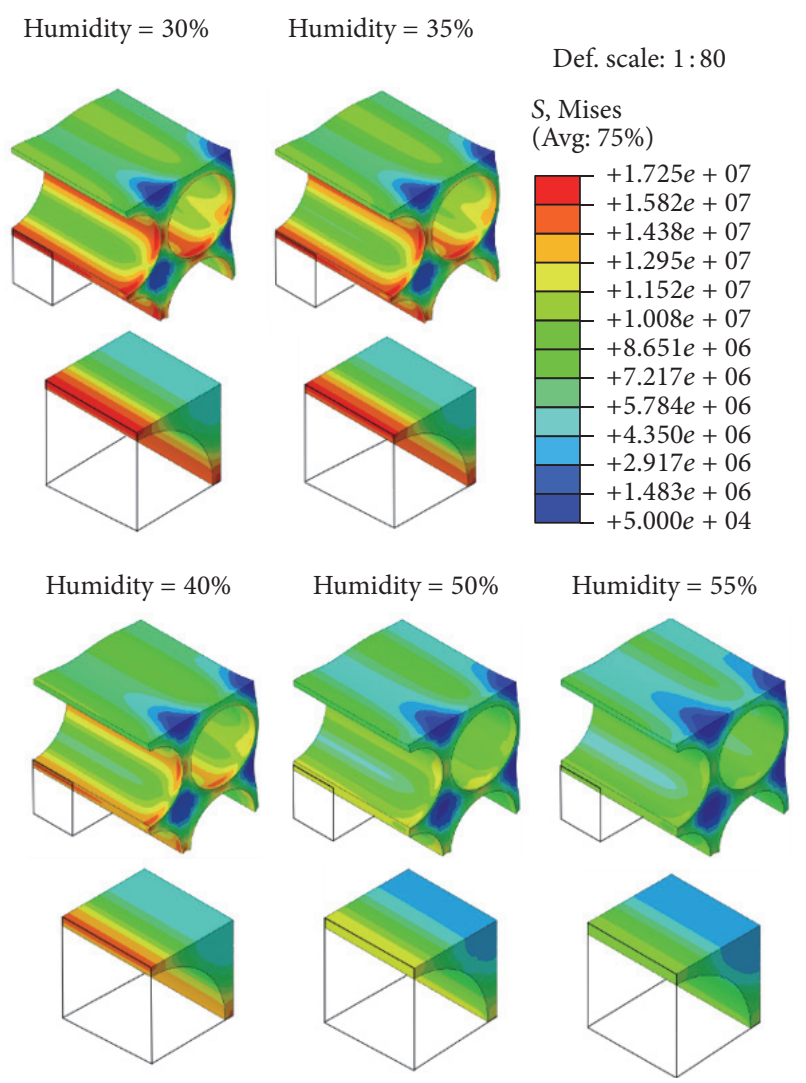

FIGURE 15: RVE under moisture expansion.

3.4. Discussion of FEA Results. Overall, from the FEA results, the overall effect of including residual stresses at the micromechanical level was found to be minimal with a maximum influence of $4 \%$. From the results obtained using the micromechanical analysis performed on the square RVE, it was found that the magnitude of the principal stresses was less than $\sim 7 \mathrm{MPa}$ at the critical locations identified in Figure 17. The significance of this value can be properly understood by referring to a previous investigation which examined the same material (EP 280 Prepreg) under tensile loading [9]. In that investigation, it was identified that the matrix is best modelled using the First-Stress Invariant when failure takes place due to an increase in volume $[3,9]$. The hygrothermal stresses obtained in this investigation are added onto the results of the previous investigation using (1). Note that, due to the higher mechanical stress components, the critical location on the matrix occurs at P3 (Figure 17). Thus, the First-Stress Invariant is found to increase by $4.509 \mathrm{MPa}$ due to incorporating hygrothermal effects from the cure regime. When the authors had ignored hygrothermal effects, the failure of the matrix under biaxial tension was given by (4), where $\sigma_{1}, \sigma_{2}$, and $\sigma_{3}$ are the three principal stresses. The mechanical stresses and the newly obtained residual (hygrothermal) stresses for the various tension experiments that were performed are shown in Table 4.

$$
\sigma_{1}+\sigma_{2}+\sigma_{3}=175.4
$$

TABLE 3: Stresses at critical locations of the RVE after resting at room conditions, where $J_{1}$ is the First-Stress Invariant and $\sigma_{\mathrm{DP}}$ is the stress given by Drucker-Prager failure criterion, where $A=62.25 \mathrm{MPa}$ and $B=-0.061[10]$.

\begin{tabular}{lccccc}
\hline Location & $\sigma_{1}(\mathrm{MPa})$ & $\sigma_{2}(\mathrm{MPa})$ & $\sigma_{3}(\mathrm{MPa})$ & $J_{1}(\mathrm{MPa})$ & $\sigma_{\mathrm{DP}}(\mathrm{MPa})$ \\
\hline P1 & 5.096 & 4.780 & -5.247 & 4.629 & 61.968 \\
P2 & 7.125 & 6.180 & 1.698 & 15.003 & 61.335 \\
P3 & 5.074 & 4.750 & -5.315 & 4.509 & 61.975 \\
P4 & 6.334 & 5.223 & -5.125 & 6.432 & 61.858 \\
P5 & 6.790 & 3.566 & 3.378 & 13.734 & 61.412 \\
P6 & 6.287 & 5.158 & -5.220 & 6.225 & 61.870 \\
\hline
\end{tabular}

When a sum of least squares regression analysis is performed on the new failure data which incorporates residual stresses on the matrix, (4) changes slightly to that shown by

$$
\sigma_{1}+\sigma_{2}+\sigma_{3}=179.9 \text {. }
$$

It can be seen that the percentage difference in the value of the First-Stress Invariant due to the inclusion of hygrothermal effects due to the cure regime affects the matrix failure results by less than $3 \%$ on average. This minimal change is consistent with the proposal that hygrothermal effects can be ignored if the moisture content of the composite is $\sim 0.5 \%$.

Similarly, the residual stresses have been included into the mechanical stresses obtained for matrix failure under compressive loading examined in literature [10] (Table 5). The Drucker-Prager failure criterion was used to describe the matrix failure envelope under compressive and shear dominant loading. Equation (6) was presented as best predicting failure for EP280 Prepreg.

$$
\sqrt{J_{2}}=62.25-0.061 J_{1} \text {. }
$$

When a sum of least squares regression analysis is performed on the new failure data which incorporates residual stresses on the matrix, (6) changes slightly to that shown by (7). Both the First-Stress Invariant and Drucker-Prager failure surfaces with and without the inclusion of residual stresses from the cure regime are shown in Figure 18 which shows minimal changes. The combination of two distinctly different failure behaviours captured by the two failure surfaces has been investigated by others in literature [8-10]. From Figure 18, it can be seen that the overall failure surface remains mostly unchanged; thus, incorporation of thermal residual stresses from the cure regime can be largely ignored due to the swelling of the composite when left at lab conditions.

$$
\sqrt{J_{2}}=61.75-0.057 J_{1}
$$

\section{Hot and Cold Temperature Conditions}

The main focus of this study was to observe the significance of hygrothermal stresses at room temperature. Room temperature conditions are one of the most important cases to consider, as most material characterisation, fatigue, and strength tests are performed at this environment $[24,25]$. In 
TABle 4: Principal stresses obtained from biaxial tension experiments on EP 280 Prepreg, where $J_{1}{ }^{\text {Mech }}$ is the First-Stress Invariant based on the mechanical stresses [9] and $J_{1}{ }^{\text {Mech+Res }}$ is the First-Stress Invariant based on both the mechanical and residual stresses.

\begin{tabular}{|c|c|c|c|c|c|c|c|c|c|}
\hline \multirow{2}{*}{ Test number } & \multicolumn{3}{|c|}{ Mechanical stresses [9] } & \multicolumn{5}{|c|}{ Residual stresses } & \multirow{2}{*}{$\%$ difference } \\
\hline & $\sigma_{1}(\mathrm{MPa})$ & $\sigma_{2}(\mathrm{MPa})$ & $\sigma_{3}(\mathrm{MPa})$ & $J_{1}^{\text {Mech }}(\mathrm{MPa})$ & $\sigma_{1}(\mathrm{MPa})$ & $\sigma_{2}(\mathrm{MPa})$ & $\sigma_{3}(\mathrm{MPa})$ & $J_{1}{ }^{\text {Mech+Res }}(\mathrm{MPa})$ & \\
\hline 1 & 137.65 & 32.61 & 4.60 & 174.86 & 5.07 & 4.75 & -5.32 & 179.36 & $3 \%$ \\
\hline 2 & 95.58 & 50.92 & 33.62 & 180.12 & 5.07 & 4.75 & -5.32 & 184.62 & $2 \%$ \\
\hline 3 & 178.02 & 28.10 & -55.32 & 150.8 & 5.07 & 4.75 & -5.32 & 155.3 & $3 \%$ \\
\hline 4 & 76.54 & 44.67 & 27.80 & 149.01 & 5.07 & 4.75 & -5.32 & 153.51 & $3 \%$ \\
\hline 5 & 105.26 & 37.03 & 31.22 & 173.51 & 5.07 & 4.75 & -5.32 & 178.01 & $3 \%$ \\
\hline 6 & 70.08 & 40.51 & 25.35 & 135.94 & 5.07 & 4.75 & -5.32 & 140.44 & $3 \%$ \\
\hline 7 & 89.96 & 29.43 & 24.34 & 143.73 & 5.07 & 4.75 & -5.32 & 148.23 & $3 \%$ \\
\hline 8 & 86.80 & 49.77 & 31.23 & 167.8 & 5.07 & 4.75 & -5.32 & 172.3 & $3 \%$ \\
\hline 9 & 101.25 & 35.61 & 30.37 & 167.23 & 5.07 & 4.75 & -5.32 & 171.73 & $3 \%$ \\
\hline 10 & 112.09 & 41.38 & 35.04 & 188.51 & 5.07 & 4.75 & -5.32 & 193.01 & $2 \%$ \\
\hline 11 & 138.47 & 43.92 & 31.65 & 214.04 & 5.07 & 4.75 & -5.32 & 218.54 & $2 \%$ \\
\hline 12 & 162.05 & 54.18 & 43.34 & 259.57 & 5.07 & 4.75 & -5.32 & 264.07 & $2 \%$ \\
\hline 13 & 118.44 & 31.91 & 10.68 & 161.03 & 5.07 & 4.75 & -5.32 & 165.53 & $3 \%$ \\
\hline 14 & 149.68 & 50.57 & 41.22 & 241.47 & 5.07 & 4.75 & -5.32 & 245.97 & $2 \%$ \\
\hline 15 & 89.79 & 25.78 & 9.90 & 125.47 & 5.07 & 4.75 & -5.32 & 129.97 & $4 \%$ \\
\hline 16 & 104.41 & 44.69 & 10.80 & 159.9 & 5.07 & 4.75 & -5.32 & 164.4 & $3 \%$ \\
\hline 17 & 124.87 & 37.53 & 23.61 & 186.01 & 5.07 & 4.75 & -5.32 & 190.51 & $2 \%$ \\
\hline 18 & 79.57 & 29.42 & 25.48 & 134.47 & 5.07 & 4.75 & -5.32 & 138.97 & $3 \%$ \\
\hline 19 & 96.02 & 36.51 & 31.16 & 163.69 & 5.07 & 4.75 & -5.32 & 168.19 & $3 \%$ \\
\hline 20 & 121.95 & 46.16 & 39.50 & 207.61 & 5.07 & 4.75 & -5.32 & 212.11 & $2 \%$ \\
\hline 21 & 137.82 & 54.91 & 46.36 & 239.09 & 5.07 & 4.75 & -5.32 & 243.59 & $2 \%$ \\
\hline 22 & 107.53 & 55.18 & 40.24 & 202.95 & 5.07 & 4.75 & -5.32 & 207.45 & $2 \%$ \\
\hline 23 & 76.43 & 30.93 & 27.04 & 134.4 & 5.07 & 4.75 & -5.32 & 138.9 & $3 \%$ \\
\hline 24 & 115.96 & 50.59 & 40.71 & 207.26 & 5.07 & 4.75 & -5.32 & 211.76 & $2 \%$ \\
\hline 25 & 98.08 & 39.94 & 34.69 & 172.71 & 5.07 & 4.75 & -5.32 & 177.21 & $3 \%$ \\
\hline 26 & 68.60 & 27.53 & 24.21 & 120.34 & 5.07 & 4.75 & -5.32 & 124.84 & $4 \%$ \\
\hline
\end{tabular}

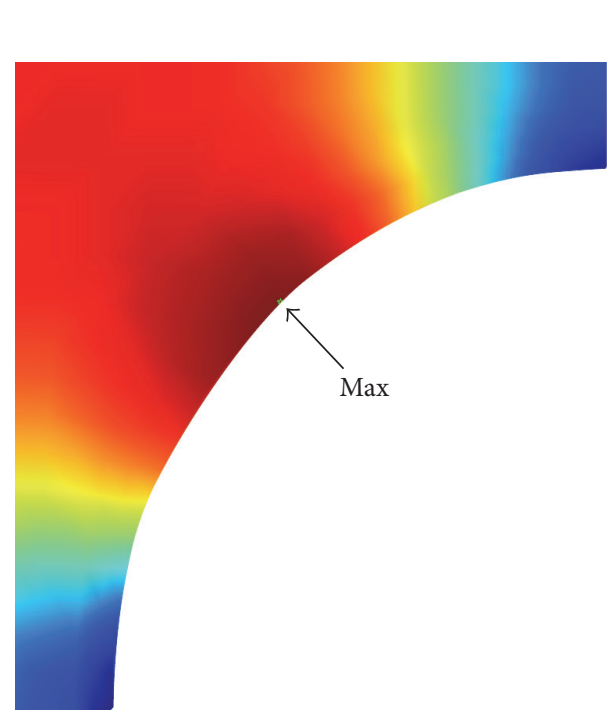

(a)

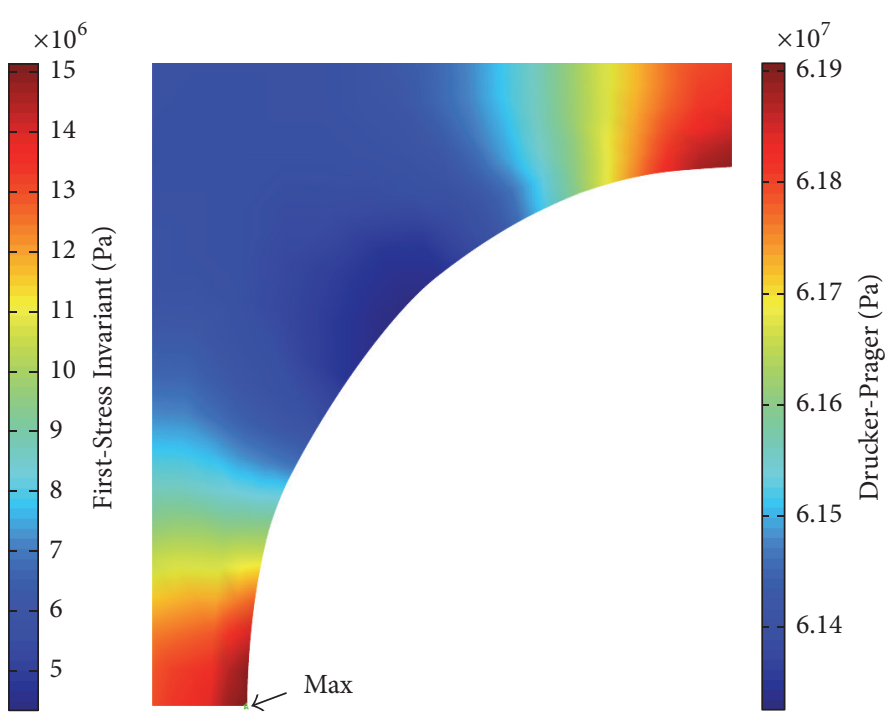

(b)

FIGURE 16: Peak stress location after both thermal contraction and moisture expansion: (a) First-Stress Invariant contour plot and (b) DruckerPrager stress contour plot. 
TABLE 5: Principal stresses obtained from compression experiments on EP 280 Prepreg.

\begin{tabular}{|c|c|c|c|c|c|c|}
\hline \multirow{2}{*}{ Test number } & \multicolumn{3}{|c|}{ Mechanical stresses [10] } & \multicolumn{3}{|c|}{ Residual stresses } \\
\hline & $\sigma_{1}(\mathrm{MPa})$ & $\sigma_{2}(\mathrm{MPa})$ & $\sigma_{3}(\mathrm{MPa})$ & $\sigma_{1}(\mathrm{MPa})$ & $\sigma_{2}(\mathrm{MPa})$ & $\sigma_{3}(\mathrm{MPa})$ \\
\hline 1 & -77.18 & -253.42 & -95.60 & 5.07 & 4.75 & -5.32 \\
\hline 2 & -86.29 & -281.52 & -106.37 & 5.07 & 4.75 & -5.32 \\
\hline 3 & -63.60 & -207.49 & -78.39 & 5.07 & 4.75 & -5.32 \\
\hline 4 & -66.01 & -227.05 & -84.19 & 5.07 & 4.75 & -5.32 \\
\hline 5 & -55.62 & -187.58 & -69.57 & 5.07 & 4.75 & -5.32 \\
\hline 6 & -57.23 & -195.18 & -72.30 & 5.07 & 4.75 & -5.32 \\
\hline 7 & -53.06 & -191.05 & -67.15 & 5.07 & 4.75 & -5.32 \\
\hline 8 & -57.59 & -207.38 & -72.89 & 5.07 & 4.75 & -5.32 \\
\hline 9 & -52.71 & -189.80 & -66.72 & 5.07 & 4.75 & -5.32 \\
\hline 10 & -49.27 & -198.03 & -64.17 & 5.07 & 4.75 & -5.32 \\
\hline 11 & -48.49 & -194.87 & -63.15 & 5.07 & 4.75 & -5.32 \\
\hline 12 & -29.40 & -154.37 & -45.24 & 5.07 & 4.75 & -5.32 \\
\hline 13 & -24.03 & -126.38 & -37.12 & 5.07 & 4.75 & -5.32 \\
\hline 14 & -30.58 & -160.81 & -47.23 & 5.07 & 4.75 & -5.32 \\
\hline 15 & 15.19 & -137.00 & -23.55 & 5.07 & 4.75 & -5.32 \\
\hline 16 & 13.90 & -125.36 & -21.55 & 5.07 & 4.75 & -5.32 \\
\hline 17 & 14.73 & -132.91 & -22.85 & 5.07 & 4.75 & -5.32 \\
\hline 18 & 22.37 & -134.04 & -22.73 & 5.07 & 4.75 & -5.32 \\
\hline 19 & 20.67 & -126.11 & -21.69 & 5.07 & 4.75 & -5.32 \\
\hline
\end{tabular}

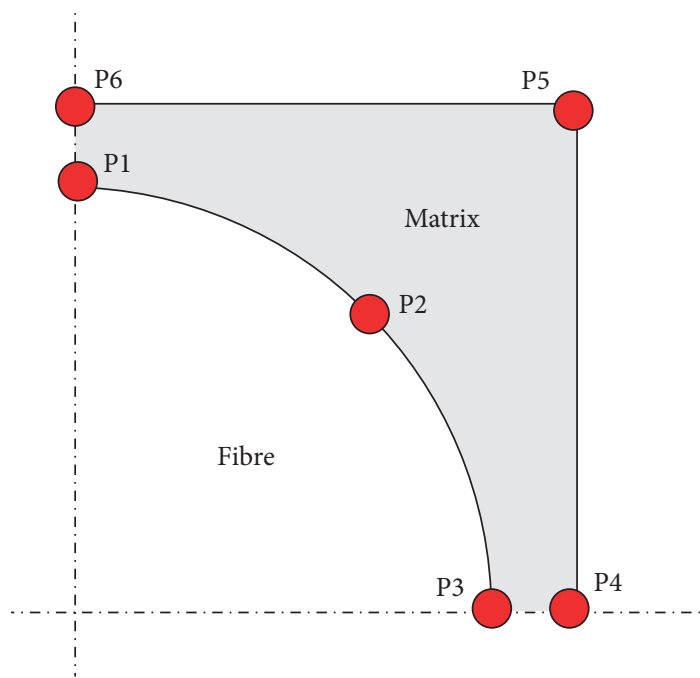

FIgURE 17: Critical location on a square RVE probed for their principal stress values.

this section, the investigation is briefly extended to demonstrate the significance of hygrothermal residual stresses on the matrix at hot and cold temperatures.

4.1. FEA Results. Based on the material specifications for EP 280 Prepreg, the manufacturers recommend safe operating conditions up to $70^{\circ} \mathrm{C}$. Thus, the hot temperature considered is $70^{\circ} \mathrm{C}$ and the cold temperature considered is $-24^{\circ} \mathrm{C}$ which was chosen to give the same temperature difference as the

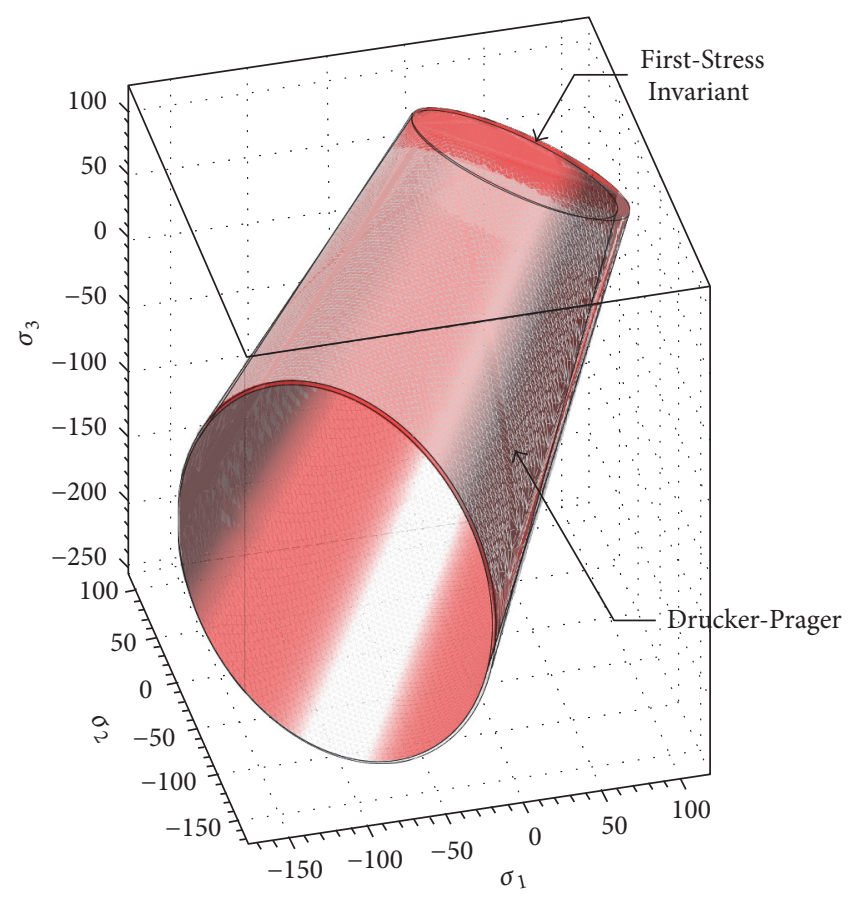

Matrix failure envelope

Only mechanical stresses

Mechanical + residual stresses

FIGURE 18: Comparison of matrix failure envelope with and without the inclusion of residual stresses introduced to composites due to the cure regime [8]. 
TABLE 6: Stresses at critical locations of the RVE for the hot temperature $\left(70^{\circ} \mathrm{C}\right)$, where $J_{1}$ is the First-Stress Invariant and $\sigma_{\mathrm{DP}}$ is the stress given by Drucker-Prager failure criterion, where $A=$ $62.25 \mathrm{MPa}$ and $B=-0.061[10]$.

\begin{tabular}{lcccccc}
\hline Condition & Location & $\begin{array}{c}\sigma_{1} \\
(\mathrm{MPa})\end{array}$ & $\begin{array}{c}\sigma_{2} \\
(\mathrm{MPa})\end{array}$ & $\begin{array}{c}\sigma_{3} \\
(\mathrm{MPa})\end{array}$ & $\begin{array}{c}J_{1} \\
(\mathrm{MPa})\end{array}$ & $\begin{array}{c}\sigma_{\mathrm{DP}} \\
(\mathrm{MPa})\end{array}$ \\
\hline Thermal & $\mathrm{P} 2$ & 5.53 & 4.76 & 1.30 & 11.59 & 61.54 \\
Moisture & $\mathrm{P} 2$ & -6.31 & -7.61 & -4.59 & -18.51 & 63.68 \\
Final & $\mathrm{P} 2$ & -0.78 & -2.85 & -3.29 & -6.92 & 62.67 \\
\hline Thermal & $\mathrm{P} 3$ & 3.87 & 3.53 & -4.06 & 3.34 & 62.05 \\
Moisture & $\mathrm{P} 3$ & -1.42 & -5.73 & 1.72 & -5.43 & 62.58 \\
Final & $\mathrm{P} 3$ & 2.45 & -2.20 & -2.34 & -2.09 & 62.38 \\
\hline
\end{tabular}

TABLE 7: Stresses at critical locations of the RVE for the cold temperature $\left(-24^{\circ} \mathrm{C}\right)$, where $J_{1}$ is the First-Stress Invariant and $\sigma_{\mathrm{DP}}$ is the stress given by Drucker-Prager failure criterion, where $A=$ 62.25 $\mathrm{MPa}$ and $B=-0.061[10]$.

\begin{tabular}{lcccccc}
\hline Condition & Location & $\begin{array}{c}\sigma_{1} \\
(\mathrm{MPa})\end{array}$ & $\begin{array}{c}\sigma_{2} \\
(\mathrm{MPa})\end{array}$ & $\begin{array}{c}\sigma_{3} \\
(\mathrm{MPa})\end{array}$ & $\begin{array}{c}J_{1} \\
(\mathrm{MPa})\end{array}$ & $\begin{array}{c}\sigma_{\mathrm{DP}} \\
(\mathrm{MPa})\end{array}$ \\
\hline Thermal & $\mathrm{P} 2$ & 15.95 & 13.74 & 3.79 & 33.48 & 60.21 \\
Moisture & $\mathrm{P} 2$ & -8.82 & -7.56 & -2.09 & -18.47 & 63.38 \\
Final & $\mathrm{P} 2$ & 7.13 & 6.18 & 1.70 & 15.01 & 61.33 \\
\hline Thermal & $\mathrm{P} 3$ & 11.24 & 10.53 & -11.79 & 9.98 & 61.64 \\
Moisture & $\mathrm{P} 3$ & -6.21 & -5.94 & 6.51 & -5.64 & 62.59 \\
Final & $\mathrm{P} 3$ & 5.03 & 4.59 & -5.28 & 4.34 & 61.99 \\
\hline
\end{tabular}

hot condition, however below room temperature. The results from the FEA are shown in Tables 6 and 7, respectively. Moisture levels chosen to analyse the RVE models were taken to be the same as discussed earlier in this paper where their magnitudes have been based on inference.

4.2. Discussion of FEA Results. From Table 6, it can be seen that the matrix residual stresses due to hygrothermal effects are significantly in tension before consideration of moisture swelling. With the consideration of swelling used in the previous investigation, it is found that the residual stresses change to a slight compressive nature which according to Figure 18 would fall on the Drucker-Prager Surface. However, the magnitude of the residual stresses suggests that no significant changes to the material's failure envelope would take place for this particular material. It should be noted that, depending on the recommended operating temperatures for certain materials and its characteristics, the significance of the residual stresses may change. As this example clearly highlights the fact that the mode of load experienced on the matrix has changed from a dilatational to a distortional mode.

Looking at the results of Table 7, the cold temperature condition results in a significant tensile load on the matrix as a result of the residual stresses. Location P2 (Figure 17) experienced the highest stress in the fibre direction with a value of $\sim 16 \mathrm{MPa}$. If only thermal residual stresses were considered for the material, then these results would suggest that the residual stresses would be very important to include in a structural analysis using this material. Once the effects of moisture swelling have been considered, there is approximately a $56 \%$ recovery of residual stresses which still results in a tensile load on the matrix; however, their magnitude becomes less critical.

4.3. Future Work. The work presented in this paper highlights the potential for including residual stresses within the micromechanical level of analysis in composite materials. Although, for the particular material system discussed in this paper, the effects were stated to be minimal and thus ignorable, this may be a different case for others using different material systems which are exposed to different operating environments and loads. The inclusion of this work in examining initial failure in composites can have the potential to significantly affect failure predictions in progressive damage models which are gaining popularity within the research industry.

\section{Conclusions}

The overall conclusion drawn from these tests is that thermal residual strains for the composite material being examined (EP280) can be offset if it can be proved that the environmental conditions in which the specimens are stored result in the swelling of the material due to moisture absorption. In this experiment examining a composite prepreg material (EP280), the thermal and moisture effects were found to have almost a one-to-one relationship. Further analysis, using representative volume elements in FEA, found the swelling of the composite after it contracts due to the cure regime to have a significant effect, up to the point where analysis of matrix failure experiment results published in literature is found to differ by less than $3 \%$ on average. On the other hand, a brief look at hygrothermal residual stresses at hot $\left(70^{\circ} \mathrm{C}\right)$ and cold conditions $\left(-24^{\circ} \mathrm{C}\right)$ revealed that the magnitude of these stresses can change significantly compared to at room temperature, and, without incorporating moisture swelling, the results would have an important effect on any failure analysis. It was found that, for the hot condition, the residual stresses due to thermal stresses changed from a tensile load on the matrix to a slight compressive load. Whilst, for the cold conditions, approximately $56 \%$ of the thermal residual stresses were recovered due to moisture absorption.

Thus, residual stresses introduced to the composite due to its cure regime were found to be insignificant for composites with a moisture content of $\sim 0.5 \%$ when allowed to rest at ambient lab conditions. However, when hot and cold environments are considered, the significance of these stresses is more prominent and it is important to perform a similar investigation to justify their significance which for the case of EP 280 Prepreg used in this study was found to not be significant.

\section{Competing Interests}

The authors declare that they have no competing interests. 


\section{References}

[1] A. C. Orifici, I. Herszberg, and R. S. Thomson, "Review of methodologies for composite material modelling incorporating failure," Composite Structures, vol. 86, no. 1-3, pp. 194-210, 2008.

[2] J. H. Gosse and S. Christensen, "Strain invariant failure criteria for polymers in composite materials," in Proceedings of the 19th AIAA Applied Aerodynamics Conference, June 2001.

[3] L. J. Hart-Smith, "Application of the strain invariant failure theory (SIFT) to metals and fiber-polymer composites," Philosophical Magazine, vol. 90, no. 31-32, pp. 4263-4331, 2010.

[4] Firehole Technologies, Helius: MCT Technical Manual Version 1.0, 2009 .

[5] J. S. Welsh, J. S. Mayes, C. T. Key, and R. N. McLaughlin, "Comparison of MCT failure prediction techniques and experimental verification for biaxially loaded glass fabric-reinforced composite laminates," Journal of Composite Materials, vol. 38, no. 24, pp. 2165-2181, 2004.

[6] J. M. Snead and A. N. Palazotto, "Moisture and temperature effects on the instability of cylindrical composite panels," Journal of Aircraft, vol. 20, no. 9, pp. 777-783, 1983.

[7] A. Zafar, F. Bertocco, J. Schjødt-Thomsen, and J. C. Rauhe, "Investigation of the long term effects of moisture on carbon fibre and epoxy matrix composites," Composites Science and Technology, vol. 72, no. 6, pp. 656-666, 2012.

[8] N. T. Chowdhury, J. Wang, W. K. Chiu, and W. Yan, "Predicting matrix failure in composite structures using a hybrid failure criterion," Composite Structures, vol. 137, pp. 148-158, 2016.

[9] N. T. Chowdhury, J. Wang, W. K. Chiu, and W. Yan, "Matrix failure in composite laminates under tensile loading," Composite Structures, vol. 135, pp. 61-73, 2016.

[10] N. T. Chowdhury, J. Wang, W. K. Chiu, and W. Yan, "Matrix failure in composite laminates under compressive loading," Composites Part A: Applied Science and Manufacturing, vol. 84, pp. 103-113, 2016.

[11] A. K. Kaw, Mechanics of Composite Materials, Taylor \& Francis, 2nd edition, 2005.

[12] GMS Composites Standard Prepreg Range \& Technical datasheets (EP 280), October 2015, http://www.gmscomposites.com/ prepreg-range/prepreg-technical-datasheets/.

[13] M. Brieu, J. Diani, and N. Bhatnagar, "A new biaxial tension test fixture for uniaxial testing machine-a validation for hyperelastic behavior of rubber-like materials," Journal of Testing and Evaluation, vol. 35, no. 4, pp. 364-372, 2007.

[14] ASTM International, "Standard test method for moisture absorption properties and equilibrium conditioning of polymer matrix composite materials," ASTM D 5229, 2014.

[15] ASTM D 6641, "Standard test method for compressive properties of polymer matrix composite materials using a Combined Loading Compression (CLC) test fixture," ASTM, 2011.

[16] C. Wang, "A multi-scale progressive damage model for laminates," Australian Journal of Mechanical Engineering, vol. 3, no. 1, p. 73, 2006.

[17] S. W. Tsai, Theory of Composites Design, Think Composites Dayton, 1992.

[18] J. N. Reddy, Mechanics of Laminated Composite Plates and Shells: Theory and Analysis, Taylor \& Francis, 2nd edition, 2004.

[19] X. Li, Z. Guan, Z. Li, and L. Liu, "A new stress-based multi-scale failure criterion of composites and its validation in open hole tension tests," Chinese Journal of Aeronautics, vol. 27, no. 6, pp. 1430-1441, 2014.
[20] N. T. Chowdhury, W. K. Chiu, and J. Wang, "Biaxial specimen design for structures subjected to multi-axial loads," Advanced Materials Research, vol. 891-892, pp. 1633-1638, 2014.

[21] N. T. Chowdhury, W. K. Chiu, J. Wang, and W. Yan, "Comparison of failure criterion examining matrix dominant failure under biaxial loading," in Proceedings of the 8th Australasian Congress on Applied Mechanics (ACAM '14), pp. 579-587, Melbourne, Australia, November 2014.

[22] N. T. Chowdhury, J. Wang, and W. K. Chiu, "Design of a flat plate specimen suitable for biaxial tensile tests on polymer materials," Polymers and Polymer Composites, vol. 23, no. 9, pp. 627-638, 2015.

[23] I. M. Daniel and O. Ishai, Engineering Mechanics of Composite Materials, Oxford University Press, 2006.

[24] M. C. S. Moreno, J. L. M. Vicente, and J. J. L. Cela, "Failure strain and stress fields of a chopped glass-reinforced polyester under biaxial loading," Composite Structures, vol. 103, pp. 27-33, 2013.

[25] J. L. Wind, A. M. Waas, and H. M. Jensen, "Initiation of failure at notches in unidirectional fiber composites," Composite Structures, vol. 122, pp. 51-56, 2015. 

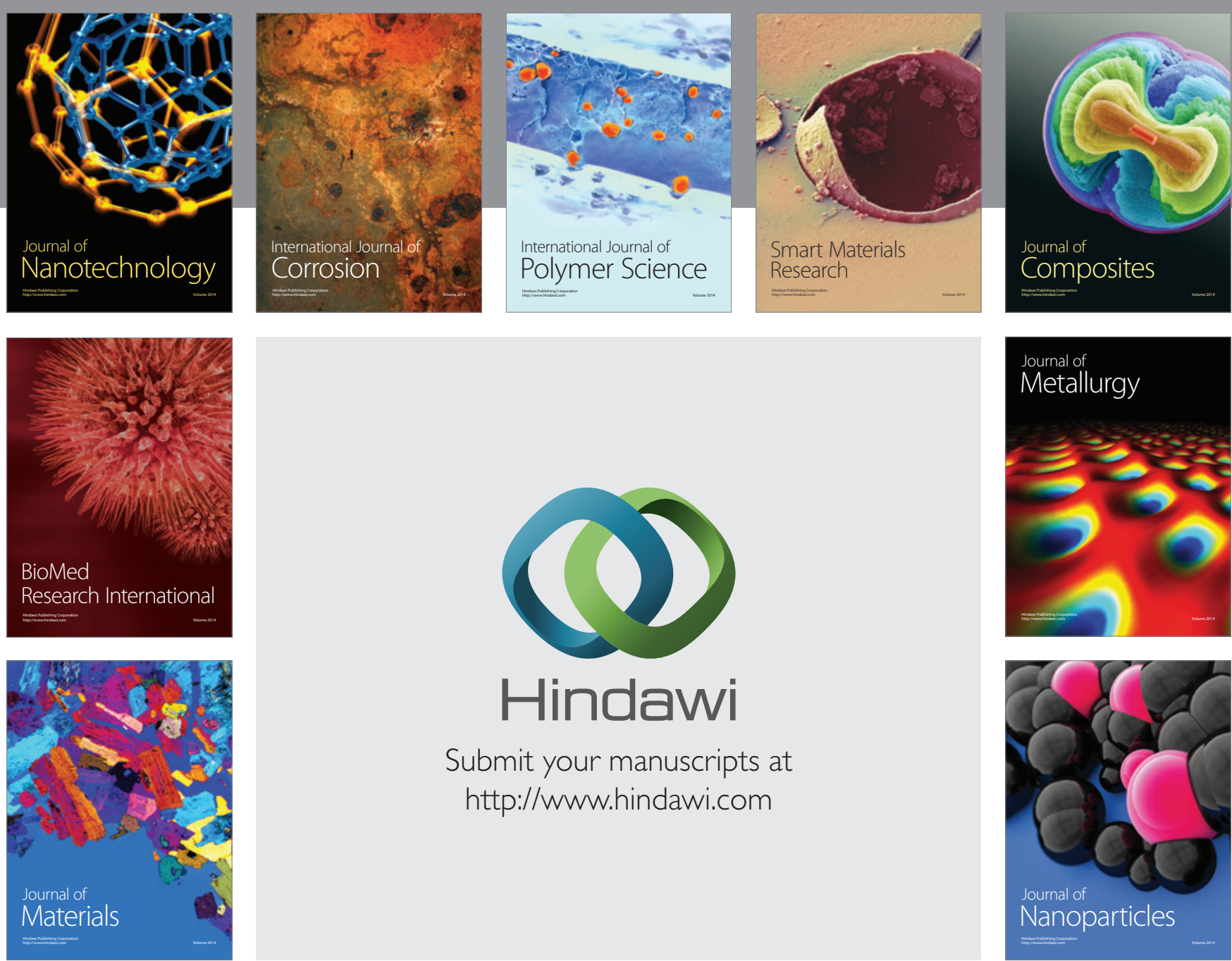

\section{Hindawi}

Submit your manuscripts at

http://www.hindawi.com

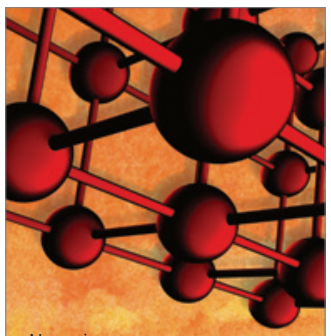

Materials Science and Engineering
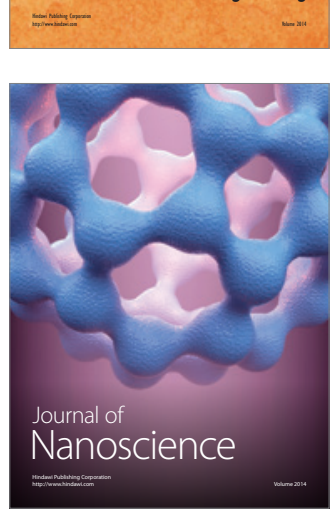
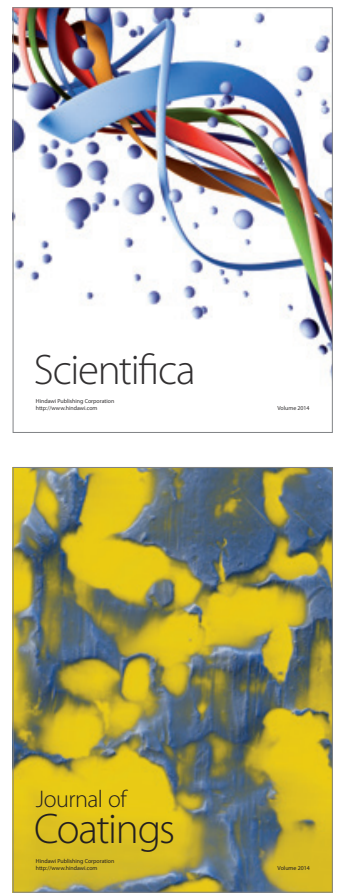
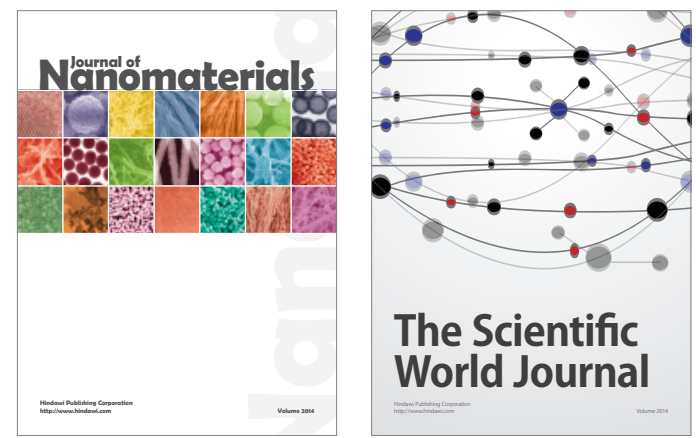

The Scientific World Journal
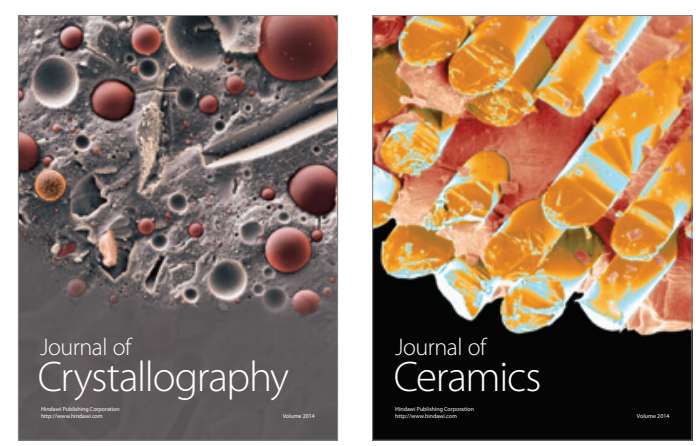
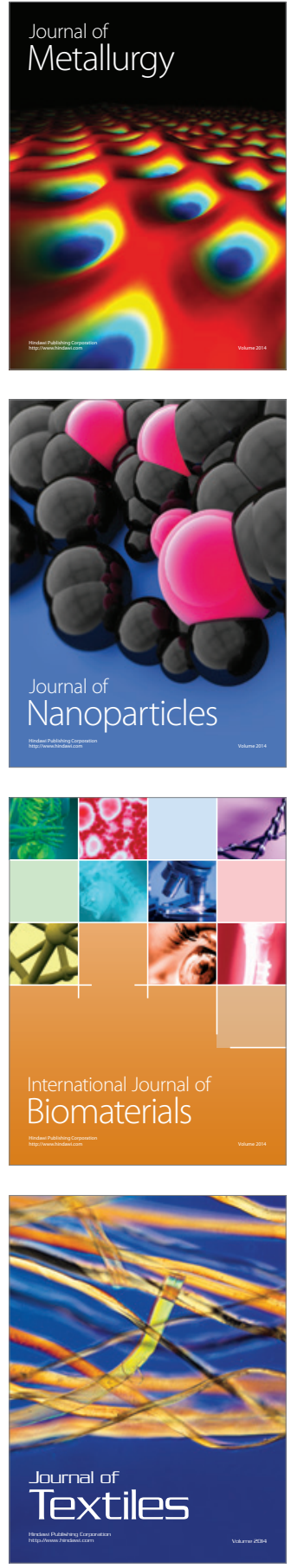